\title{
ENFERMEIROS ESPECIALISTAS EM ENFERMAGEM DE SAÚDE INFANTIL E PEDIATRIA E PROMOÇÃO DA AMAMENTAÇÃO APÓS O REGRESSO AO TRABALHO
}

\author{
Dulce Maria Pereira Garcia Galvão \\ Pós Doutoramento em Enfermagem, Professora Coordenadora; Escola Superior de Enfermagem de Coimbra - \\ ESEnfC - Coimbra, Portugal; dgalvao@esenfc.pt \\ Cátia da Mota Cardoso \\ Mestre em Enfermagem de Saúde Infantil e Pediatria, Enfermeira; catita678@hotmail.com \\ https://doi.org/10.17060/ijodaep.2017.n1.v3.984
}

Fecha de Recepción: 18 Marzo 2017

Fecha de Admisión: 1 Abril 2017

\begin{abstract}
RESUMO
Antecedentes: Em Portugal, apesar das iniciativas desenvolvidas para promover 0 aleitamento materno, as taxas e suas práticas continuam abaixo do recomendado pela OMS. A generalidade das mulheres decide e é favorável à amamentação. Trabalhar fora de casa tornou-se uma realidade para a maioria das mulheres. Por vezes torna-se difícil conciliar 0 aleitamento materno com a atividade laboral e 0 regresso ao trabalho encontra-se entre um dos motivos apontados pelas mães para 0 abandono precoce da amamentação. Promover a amamentação é uma prioridade de saúde pública. As atitudes e intervenções dos enfermeiros exercem influência no processo/sucesso da amamentação e no ultrapassar de dificuldades que surgem. Objetivos: Conhecer as medidas promotoras da amamentação que os enfermeiros dos cuidados de saúde primários, especialistas em Enfermagem de Saúde Infantil e Pediatria, desenvolvem no sentido de apoiar as mães que trabalham a continuar a amamentar e identificar as intervenções promotoras da amamentação desenvolvidas por estes enfermeiros junto das mães, a nível da comunidade, na família, nos locais de trabalho, nas creches e nos seus próprios locais de trabalho. Participantes e Métodos: Estudo descritivo, transversal, segundo a metodologia qualitativa, junto de 13 enfermeiros Especialistas em Enfermagem de Saúde Infantil e Pediatria que trabalham em Centros de Saúde de um Agrupamento de Centros de Saúde. Colheram-se dados por entrevista semiestruturada entre Junho e Julho de 2015. No tratamento da informação recorreu-se à análise de conteúdo de Laurence Bardin. Resultados: Os Enfermeiros embora despertos para a necessidade de promover a manutenção da amamentação após o regresso das mães ao trabalho desenvolvem, predominantemente no contexto das consultas de enfermagem, várias intervenções (cantinhos da amamentação, apoio telefónico, visita domiciliária, ensinos, comemoração da semana mundial do aleitamento materno) junto das mães, pais e avós.
\end{abstract}




\section{ENFERMEIROS ESPECIALISTAS EM ENFERMAGEM DE SAÚDE INFANTIL E PEDIATRIA E PROMOÇÃO DA AMAMENTAÇ̃̃O APÓS O REGRESSO AO TRABALHO}

Conclusões: A atuação dos Enfermeiros resume-se ao contexto das consultas de enfermagem. Há contudo, outros locais onde as intervenções de enfermagem devem chegar, nomeadamente, creches, entidades patronais e sociedade em geral, com vista a reduzir o desmame precoce motivado pelo regresso das mães ao trabalho.

Palavras-chave: Aleitamento Materno; Mulheres Trabalhadoras; Enfermagem Pediátrica; Cuidados de Saúde Primários.

\section{ABSTRACT \\ Nurses Specialist in Child Health and Pediatrics and promotion of breastfeeding after the return to work \\ Background: In Portugal, breastfeeding rates are still below those recommended by the World} Health Organization, despite the initiatives for its promotion. Most women choose and are favorable to breastfeeding. Working outside the home has become a reality for most women, and reconciling breastfeeding with the professional activity is often difficult. Thus, the return to work is one of the reasons mentioned by mothers for early breastfeeding cessation. The promotion of breastfeeding is a public health priority. Nurses' attitudes and interventions influence the success of breastfeeding and help overcome some of the difficulties encountered. Objectives: To identify measures developed by primary care nurses specialized in Child Health and Pediatrics to promote breastfeeding and encourage working mothers to continue breastfeeding, as well as identify these nurses' interventions toward the promotion of breastfeeding in the community, family, workplace, and day-care centers. Participants and Methods: Descriptive, cross-sectional study with a quantitative methodology using a sample of 13 nurses specialized in Child Health and Pediatrics working in Health Care Centers of a Cluster of Health Centers. Data were collected through semi-structured interviews between June and July 2015. Dara were analyzed using Bardin's content analysis technique. Results: Aware of the need to promote breastfeeding after the mother's return to work, nurses implement multiple interventions targeted at mothers, fathers, and grandparents ("breastfeeding corners", phone support services, home visits, training sessions, celebration of the World Breastfeeding Week) in nursing consultations. Conclusions: Nurses only intervene in nursing consultations. However, there are other places where nurses should intervene, namely day-care centers, the workplace, and the community in general, with the purpose of reducing early breastfeeding cessation due to the mothers' return to work

Keywords: Breastfeeding; Women, Working; Pediatric Nursing; Primary Health Care.

\section{INTRODUÇÃO}

Em Portugal a taxa de amamentação ao nascimento é elevada (superior a 95\%), porém o abandono precoce é uma realidade com que nos deparamos com alguma frequência, pelo que a sua proteção, promoção e suporte constitui uma prioridade de saúde pública. Vários são os fatores que conduzem a tal situação (Galvão, 2006). 0 regresso ao trabalho encontra-se entre um dos motivos apontados pelas mães. 0 tipo de ocupação, o regime de trabalho, as leis da maternidade vigentes e o suporte dado ao aleitamento materno no próprio ambiente de trabalho, influenciam a duração e tipo de amamentação (Pedroso, Galvão \& Castro, 2014).

No dizer de Galvão (2006) também as práticas dos profissionais de saúde se destacam como uma das medidas mais influentes para 0 aumento da prevalência e duração da amamentação. Os profissionais de saúde são o recurso mais próximo das mulheres/mães, quer durante a gravidez, parto e pós-parto, em que as suas atitudes e intervenções exercem uma grande influência no processo/sucesso da amamentação e no ultrapassar de dificuldades que possam surgir. 
Questionámo-nos: Que práticas desenvolvem os Enfermeiros Especialistas em Enfermagem de Saúde Infantil e Pediatria (ESIP) na sua atividade profissional em Cuidados de Saúde Primários (CSP), no sentido de apoiarem as mães que trabalham a continuarem a amamentar após o regresso ao trabalho? e definimos como objectivos conhecer as medidas promotoras da amamentação que os enfermeiros dos CSP, especialistas em ESIP, desenvolvem no sentido de apoiarem as mães que trabalham a continuar a amamentar e identificar as intervenções promotoras da amamentação desenvolvidas pelos enfermeiros junto das mães, na comunidade, na família, nos locais de trabalho, nas creches e nos seus próprios locais de trabalho, que ajudem as mães a manter a amamentação após o regresso ao trabalho.

\section{MÉTODOS}

Desenvolveu-se um estudo descritivo e transversal segundo a metodologia qualitativa utilizando-se a entrevista semiestruturada, com início após autorização e aprovação da Comissão de Ética da UICISA:E (Parecer № P280-04/2015), Comissão de Ética para a Saúde da Administração Regional de Saúde do Centro (Parecer № 43/2015), Diretor Executivo do ACES Baixo Mondego e Representantes máximos de Enfermagem de cada Centro de Saúde incluído no estudo, junto de Enfermeiros Especialistas em ESIP a exercer funções nos Centros de Saúde do ACES Baixo Mondego, recorrendo a uma amostra não aleatória por conveniência, que decorreu entre 2 de Junho e 6 de Julho de 2015.

Definimos como critérios de elegibilidade para a seleção dos participantes: possuir a pós-licenciatura de especialização em ESIP; exercer funções em CSP no ACES Baixo Mondego; encontrar-se na prestação direta de cuidados e aceitar participar no estudo. Antes de cada entrevista, os participantes foram informados do tema, âmbito, objetivos do trabalho, confidencialidade dos dados, finalidade e metodologia adotada, através de contacto telefónico sendo nessa altura solicitada a colaboração e agendada a entrevista, mediante a disponibilidade dos participantes. Foi-Ihes pedida autorização para gravação da entrevista e combinada a melhor forma para a sua posterior validação.

As entrevistas, com tempo médio de duração de 15-20 minutos, foram efetuadas nas instituições de trabalho dos participantes, em locais tranquilos e onde a possibilidade de ocorrerem interrupções era reduzida. 0 método escolhido para proceder à análise dos dados, tendo em conta o tipo de estudo e seus objetivos, foi a análise de conteúdo de Laurence Bardin.

Após a transcrição e análise das entrevistas, as gravações foram destruídas. Ao longo do estudo os entrevistados serão denominados de E1 a E13, de acordo com a ordem numérica de realização das entrevistas.

Participaram no estudo 13 enfermeiros, 11 do sexo feminino e dois do masculino, com média de idade de 49 anos. Em média trabalhavam na profissão e em CSP há 26,2 e 18,4 anos, respectivamente. Eram Enfermeiros ESIP entre 2 e 22 anos. Das 11 enfermeiras ESIP todas tinham filhos amamentados, em média durante 6,5 meses. Dos 13 entrevistados 3 trabalhavam em Unidades de Cuidados Continuados, 6 em Unidades de Saúde Familiar (USF) e 4 em Unidades de Cuidados de Saúde Personalizados.

\section{RESULTADOS}

Da leitura e análise das entrevistas emergiram três temas. 


\section{ENFERMEIROS ESPECIALISTAS EM ENFERMAGEM DE SAÚDE INFANTIL E PEDIATRIA E PROMOÇÃO DA AMAMENTAÇ̃̃O APÓS O REGRESSO AO TRABALHO}

Tabela 1

Temas emergentes da leitura e análise das entrevistas

População Alvo das Medidas Promotoras da Amamentação

Local de Desenvolvimento das Medidas Promotoras da Amamentação

Estratégias Promotoras da Amamentação Desenvolvidas pelos Enfermeiros

\section{POPULAÇ̃̃O ALVO DAS MEDIDAS PROMOTORAS DA AMAMENTAÇÃO}

Os enfermeiros ESIP desenvolvem medidas promotoras da amamentação junto de Mães, Pais, Avós e Crianças.

\section{Mães}

A intervenção dos enfermeiros ESIP junto das mães centrou-se no Período Pré-natal e no Período Pós-natal.

No Período Pré-natal identificaram as consultas de vigilância da gravidez e sessões formativas para a grávida como momentos fundamentais para a promoção da amamentação após o regresso ao trabalho.

"A promoção da amamentação é algo que aqui fazemos sempre, não apenas quando as mães regressam ao trabalho ou quando isso se perspetiva mas sempre que temos oportunidade de contactar com elas". E1

"(...) a amamentação começava a ser abordada nas consultas de vigilância da gravidez (...). E2

"Às vezes fazemos sessões para grávidas, quando temos um grupo de grávidas...e fazemos sessões...hah, para explicar...para explicar os... os benefícios do aleitamento materno". E8

"(...) nós também temos aqui um curso de preparação para o parto, que é muito útil. Mas nós começamos a falar no aleitamento materno quando elas estão grávidas, começamos logo a motivar, não é?!"E10.

No Período Pós-natal os enfermeiros, identificaram a introdução de novos alimentos na dieta da criança, como uma forma de auxiliar as mães a manter a amamentação após o regresso ao trabalho.

“(...) a criança por vezes também já iniciou a diversificação alimentar, mas de qualquer maneira tentamos sempre que mãe continue com a amamentação (...) “. E4

"No regresso ao trabalho... hah...também Ihes vamos explicando e vamos dizendo que têm de ir começar a trabalhar...nós também Ihes dizemos para iniciar a sopa, não é?!". E9

Pais

Foram alvo de medidas promotoras da amamentação pelos enfermeiros ESIP apenas quando se dirigiram às consultas de enfermagem, enquanto acompanhantes das mães.

"(...) normalmente são as mães que vêm mas se os pais vierem à consulta também as dirigimos a eles, aos dois.". E1

"As intervenções são dirigidas ao casal, à partida ... ou ao acompanhante". E12

Avós

Também as avós foram incluídas nas atividades promotoras da amamentação, sobretudo enquanto acompanhantes das mães.

"Quando os avós ficam com os netos normalmente vêm com as mães às consultas. Sobretudo 
depois quando é essa fase da preparação para... de se prepararem para o regresso ao trabalho". E8

"(...) na generalidade, quando é necessário chamamos os avós mas isso não é no aleitamento dito normal, é em situações problemáticas. Nas situações em que realmente eles ficam com os avós nós chamamo-los para a consulta". E3

\section{Crianças}

As Crianças, de diferentes faixas etárias, apareceram também nos discursos.

“.... quando falamos por exemplo da sexualidade, e falamos das mamas, falamos da função da mama que é amamentar o bebé e salientamos muito aquela perspetiva de ... o leite da mãe é a melhor coisa para o bebé". E2

"Abordamos, portanto, com os miúdos do 1ํociclo, costumamos abordar...tanto que eles estudam já os mamíferos e falamos do aleitamento materno, de uma forma...simples (...)Também falamos com os pré-escolares...ahah...". E4

\section{LOCAL DE DESENVOLVIMENTO DAS MEDIDAS PROMOTORAS DA AMAMENTAÇÃO}

Local de Desenvolvimento das Medidas Promotoras da Amamentação foi outro dos temas emergentes nos discursos dos enfermeiros, tendo como resultado as categorias:

\section{Consultas de Enfermagem}

Foram o local onde, preferencialmente, os enfermeiros ESIP desenvolveram intervenções dirigidas à promoção da amamentação após o regresso das mães ao trabalho.

“Não, não, não. Nada. Nem amas, nem creches"E5.

"(...) essas questões vão sendo trabalhadas ao longo das vindas às consultas, (...) a nossa intervenção é durante a consulta. 0 contacto é sempre em contexto de consulta”. E6

"Para além das paredes do centro de saúde...torna-se muito complicado, porque não há tempo para isso". E7

"Não...Não fazemos nada em relação às entidades patronais". E8

"Nós não, não temos ido. Enquanto unidade de saúde familiar não vamos muito lá para fora". E9

Domicílio

Surgiu apenas no relato dos enfermeiros, após o parto.

"Nós vamos ao domicílio. Nós fazemos visita domiciliária pós parto e tentamos conciliar com uma avaliação do método de aleitamento". E10

\section{ESTRATÉGIAS PROMOTORAS DA AMAMENTAÇÃO DESENVOLVIDAS PELOS ENFERMEIROS}

Dos discursos dos enfermeiros ESIP foi possível destacar que estes destacaram como Estratégias Promotoras da Amamentação os Cantinhos da Amamentação, Apoio Telefónico, Visitação Domiciliária, Ensinos e Comemoração da Semana Mundial do Aleitamento Materno.

“(...) até têm os cantinhos da amamentação. Temos dois aqui. São usados pelas utentes e pelas colegas, se necessário". E2

"Temos cá um cantinho da amamentação e sempre que uma mãe queira dar mama ao seu bebé (...) porque a mãe não precisa dar mamita na sala de espera”. E7

"(...) ou quando têm alguma dúvida e telefonam". E5

"Telefonam...também. Damos-Ihe sempre o número de telefone para ligarem. Se não puderem cá vir a gente desloca-se lá, ao domicílio...". E9

"Nós vamos ao domicílio. Nós fazemos visita domiciliária pós parto e tentamos conciliar com uma avaliação do método de aleitamento". E10

"(...) pedia-Ihes mesmo que o fizessem (amamentassem) e corrigia alguma coisa que achasse que estava menos bem e elogiava os aspetos positivos todos que encontrasse". E2 


\section{ENFERMEIROS ESPECIALISTAS EM ENFERMAGEM DE SAÚDE INFANTIL E PEDIATRIA E PROMOÇÃO DA AMAMENTAÇ̃̃O APÓS O REGRESSO AO TRABALHO}

"E claro, nas consultas avaliamos sempre a pega e fazemos uma pesagem mais frequente em alguns casos, para ter a certeza de que a criança mama o suficiente". E10

"E começamos a fazer um trabalho logo desde o início, ensinando-Ihes sobre a legislação, logo nas consultas, e a forma de usufruir da legislação e adaptar ao trabalho, à distância do trabalho (...)". E3

"e depois falamos de legislação, relativamente aos direitos que a mãe tem no regresso ao trabalho". E11

“(...) também na forma de extrair e conservar o leite materno (...)”. E3

“(...) mesmo antes de irem trabalhar eu vou dizendo sempre que se tiverem muito leite, entre as mamadas, para retirarem o leite e congelarem (...) no local de trabalho, mais ou menos à hora que dariam a mama, continuam a retiram o leite (...)". E5

"Fizemos uma vez uma experiência aqui, numa das semanas da amamentação (...) pretendíamos criar um de grupo de apoio, entre aspas, de mães que amamentam (...) apareceram-nos duas mães. Nunca mais fizemos nada". E2

"É assim, na altura da semana do aleitamento materno nós temos sempre qualquer coisa que fazemos". E11

"Na semana da amamentação é que criamos algumas atividades, estratégias...e aí sim, envolvemos a comunidade em geral (...) Sobre a amamentação só na semana da amamentação". E13

\section{DISCUSSÃO}

Reconhecem-se alguns períodos particularmente sensíveis, que solicitam cuidados especiais por parte dos enfermeiros, com vista ao aleitamento materno bem-sucedido: durante a gravidez (especialmente no terceiro trimestre da gravidez), no pós-parto imediato (ainda em contexto hospitalar e quando se estabelece a lactação), na adaptação ao domicílio e, mais tarde, no regresso da mãe ao trabalho (Alves, 2014).

Também os enfermeiros ESIP se preocupam em abordar a amamentação às mães, ainda antes do parto. Porém, essa abordagem não é feita de uma forma sistematizada. A informação é transmitida à grávida quer durante as consultas de vigilância da gravidez, quer em sessões mais formais de preparação para o parto e para a parentalidade, estas em alguns casos a cargo de enfermeiros Especialistas em Enfermagem de Saúde Materna e Obstétrica. A questão da amamentação após 0 regresso ao trabalho não é abordada, efetivamente, embora os participantes afirmem ser importante fazê-Io neste período. Graça, Figueiredo e Conceição (2011) são defensoras de que as intervenções que se iniciam no pré-natal, continuam no pós-parto, e se prolongam no tempo, são mais eficazes do que aquelas que se limitam apenas a um desses períodos. No nosso estudo verificou-se que os participantes desenvolvem medidas promotoras da amamentação após o parto, depreendendo-se pelas suas afirmações que neste período incentivam a introdução de novos alimentos na dieta da criança, face à proximidade do regresso da mãe ao trabalho. Contudo, é evidente nos seus discursos que a finalidade desta intervenção é a manutenção da lactação e não 0 desmame precoce.

Relativamente aos pais e às avós os enfermeiros ESIP estão conscientes da sua importância e influência junto da mulheres. Aos pais, elementos habituais nas consultas de enfermagem, eram dirigidas as mesmas intervenções que às mães e que por sua vez as avós, não tão assíduas às consultas, quando necessário são convocadas para estarem presente. Também Franco e Gonçalves (2014), Maia (2007), Silva, Santiago e Lamonier (2012), comungam da opinião que a postura do pai é determinante para o sucesso do aleitamento materno. No mesmo sentido Franco e Gonçalves (2014) e Susin, Giugliani e Kummer (2005) afirmam que as avós desempenham uma influência importante, pelo aconselhamento que prestam, na sua duração e exclusividade. 
Ficou também patente no discurso dos participantes que as suas intervenções são dirigidas ainda às crianças de diferentes faixas etárias. Contudo, trata-se de uma abordagem geral sobre amamentação e não inclui a sua promoção aquando do regresso das mães ao trabalho.

Para Galvão e Silva (2011) a introdução deste tema nas escolas é uma forma privilegiada das crianças se familiarizarem com esta prática, colmatando o atual distanciamento das famílias em relação a este processo. Já em 2006 Galvão afirmava que transmitir informações sobre amamentação às crianças em idade escolar é importante, uma vez que a escola representa o espaço de aquisição de conhecimentos que tendem a perpetuar-se e a influenciar as atitudes na vida adulta.

No contexto das consultas de enfermagem (primeiramente nas consultas de vigilância da gravidez e posteriormente nas consultas de saúde infantil), os enfermeiros têm a melhor oportunidade de promover e apoiar o aleitamento materno e a sua manutenção após o regresso da mulher ao trabalho, num espaço tranquilo e sem interrupções, porém não se podem limitar a este local (Maia, 2007; OE, 2010). No nosso estudo verificámos que os enfermeiros privilegiam 0 contexto das consultas para a promoção da amamentação após o regresso das mães ao trabalho. 0 discurso dos enfermeiros ESIP permitiu-nos observar que as intervenções a nível do domicílio são pontuais, apenas no pós-parto e após a alta hospitalar, sendo que o objetivo dessa intervenção é a manutenção da amamentação nesse momento e não na altura do regresso das mães ao trabalho.

Uma intervenção promotora da amamentação após o regresso das mães ao trabalho que emergiu nos discursos dos participantes foram os cantinhos da amamentação, identificados por estes apenas como espaços de garantia de privacidade à mãe durante a amamentação.

Os cantinhos da amamentação são espaços que possibilitam o encontro de mães, a partilha de dúvidas e o esclarecimento das mesmas pelos profissionais de saúde, numa fase que pode ser crítica para as mães e crucial para a manutenção da amamentação (Maia, 2007).

0 apoio telefónico foi outra das intervenções que emergiu nos discursos. Tivemos oportunidade de constatar tratar-se de um apoio descontinuado e que acontece por iniciativa das mães. Apesar disso, o facto das mães sentirem que podem facilmente aceder aos profissionais de saúde para 0 esclarecimento de dúvidas, é por si só um fator positivo e favorecedor da manutenção da amamentação. Também Almeida, Pugliesi e Rosado (2015), se referem ao suporte telefónico, quando associado a outras intervenções, como favorecedor da manutenção da amamentação.

Outra das intervenções detetada no discurso dos participantes, com vista à promoção da amamentação após o regresso das mães ao trabalho, foi a visitação domiciliária. Os seus discursos permitiram-nos ainda depreender que se trata, na maioria das situações, de uma visita única, e que tem lugar apenas no pós-parto após a alta hospitalar, o que torna esta intervenção, apesar de benéfica, algo redutora.

A visita domiciliária é uma estratégia de intervenção que por ser realizada no ambiente da família garante um espaço mais íntimo e de pertença onde esta vê o profissional de saúde como um parceiro de cuidados, aumentando a sua autoconfiança e expondo os seus problemas, dúvidas e preocupações com mais facilidade (Filipe, 2011). A mesma autora acrescenta que, do ponto de vista do profissional de saúde, a visita domiciliária permite ter uma visão mais real das potencialidades e/ou dificuldades dos elementos da família, no contexto real em que estes se inserem, o que lhe possibilita intervir de forma mais adequada e dirigida.

0 conhecimento das técnicas adequadas e a preparação prévia para as dificuldades que podem advir da amamentação, são a base para o seu sucesso, devendo, portanto, ser 0 alicerce das medidas intervencionistas para o estímulo do aleitamento materno (Almeida, Pugliesi \& Rosado, 2015). Verificámos que os enfermeiros ESIP na promoção da amamentação após o regresso das mães ao trabalho fazem ensinos às mães sobre a técnica de amamentação, legislação que protege a mulher 


\section{ENFERMEIROS ESPECIALISTAS EM ENFERMAGEM DE SAÚDE INFANTIL E PEDIATRIA E PROMOÇÃO DA AMAMENTAÇ̃̃O APÓS O REGRESSO AO TRABALHO}

trabalhadora que amamenta e técnica de extração e conservação do leite materno. Para os participantes, dotar as mulheres de informação sobre estas três temáticas é fundamental para a manutenção da amamentação.

Outra estratégia evidenciada nos discursos dos enfermeiros ESIP como um dos momentos utilizados para difundir informação sobre amamentação à comunidade em geral para além das grávidas e mães, foi a comemoração da Semana Mundial do Aleitamento Materno. No dizer de Almeida, Pugliesi e Rosado (2015) o impacto de ações educativas únicas, isoladas e sem seguimento são pouco ou nada eficazes no que diz respeito às taxas de adesão e manutenção da amamentação.

\section{CONCLUSÃO}

Apesar dos benefícios do aleitamento materno, verifica-se que esta prática está ainda longe de corresponder ao preconizado pela OMS que recomenda a amamentação exclusiva até aos 6 meses de idade e com alimentos complementares até aos 2 anos ou mais.

0 regresso das mães à sua atividade profissional é uma das razões identificadas que contribui para o desmame precoce, pelo que cresce a necessidade de uma efetiva promoção desta prática, por parte dos profissionais de saúde competentes, neste período que é crítico para as mães.

Os enfermeiros Especialistas em ESIP que trabalham em CSP estão despertos para a necessidade de promover a manutenção da amamentação após o regresso das mães ao trabalho.

Segundo os relatos recolhidos constatou-se que são utilizadas, por estes profissionais, algumas estratégias com vista a esse fim, nomeadamente: os cantinhos da amamentação, o apoio telefónico, a visita domiciliária, a realização de ensinos (sobre a legislação, sobre a técnica de amamentação e sobre extração e conservação de leite materno) e a comemoração da Semana Mundial do Aleitamento Materno. Estas estratégias são dirigidas preferencialmente às mães (nos períodos pré e pós-natal), mas também aos pais e às avós, quando estes se dirigem às consultas enquanto acompanhantes das mães ou, esporadicamente, por convocatória.

São também alvo das suas intervenções promotoras de amamentação as crianças. Constatouse ainda que a atuação destes profissionais se limita ao contexto das consultas de enfermagem havendo necessidade de alargar as suas intervenções às creches, entidades patronais e sociedade em geral, com vista a reduzir o desmame precoce motivado pelo regresso das mães ao trabalho.

\section{REFERÊNCIAS BIBLIOGRÁFICAS}

Almeida, I.; Pugliesi, Y. \& Rosado L. (2015). Estratégias de promoção e manutenção do aleitamento materno baseadas em evidência: revisão sistemática. FEMINA. maio/junho, 43(3), p.97-103.

Alves, C. (2014). Plano de amamentação: da conceção á implementação num grupo de casais primíparos. Dissertação de Mestrado em Enfermagem de Saúde Materna e Obstétrica. Escola Superior de Enfermagem de Coimbra, Portugal.

Filipe, M. (2011). Visitação domiciliária: contributos da enfermagem na manutenção da amamentação. Dissertação de Mestrado em Enfermagem de Saúde Pública. Faculdade de Medicina da Universidade de Coimbra.

Franco, J. \& Gonçalves, V. (2014). Construção de escalas de conhecimentos e da necessidade de conhecimentos do pai sobre a amamentação. Revista da Associação Portuguesa dos Enfermeiros Obstetras. 14, p. 37-41.

Galvão, D. (2006). Amamentação bem sucedida: alguns fatores determinantes. Lusociência.

Galvão, D. \& Silva, I. (2011a). A amamentação nos manuais escolares de estudo do meio do $1^{0}$ ciclo do ensino médio. Revista de Enfermagem Referência. Série 3 (4), p. 7-16.

Galvão, D. \& Silva, I. (2011b). Conhecendo as vivências de amamentação da criança brasileira que 
frequenta 0 ensino fundamental. Revista Eletrónica de Enfermagem. jul/set; 13(3); p. 377-385. Acedido a 17/02/15. Disponível em: http://www.fen.ufg.br/revista/v13/n3/v13n3a03.htm.

Galvao, D. \& Silva, I. (2011c). Vivências de amamentação da criança portuguesa em idade escolar. Revista ESC. Enferm. USP. 45 (5), p. 1055-1062.

Graça, L.; Figueiredo, M. \& Conceição, M. (2011). Contributos da intervenção de enfermagem de cuidados de saúde primários para a promoção do aleitamento materno. Revista Latino Americana de Enfermagem. mar/abr, 19 (2), 9 p.

Maia, M. (2007). 0 papel do enfermeiro num estudo de adesão ao aleitamento materno. Dissertação de Mestrado em Ciências de Enfermagem. Instituto de Ciências Biomédicas Abel Salazar, Portugal.

Ordem dos Enfermeiros (2010). Guias orientadores de boa prática em enfermagem de saúde infantil e pediátrica. Cadernos OE. Série I, 1(3).

Ordem dos Enfermeiros (2010). Regulamento das competências específicas dos enfermeiros especialista em enfermagem de saúde da criança e do jovem. Lisboa.

Pedroso, R.; Galvão, D. \& Castro, F. (2014). Amamentação em mulheres trabalhadoras e alunas do ensino superior público de Coimbra. International Journal of Developmental and Educational Psychology. 2(1), p. 419-424.

Silva, B.; Santiago, L. \& Lamonier, J. (2012). Apoio paterno ao aleitamento materno: uma revisão integrativa. Revista Paulista de Pediatria. 30(1), p.122-130.

Susin, L.; Giugliani, E. \& Kemmer, S. (2005). Influência das avós na prática do aleitamento materno. Revista de Saúde Pública. 39(2), p.141-147. 
